\title{
THE GENETIC ORGANISATION OF NATURAL POPULATIONS OF LOLIUM PERENNE
}

\author{
IV. VARIATION WITHIN POPULATIONS
}

\author{
M. D. HAYWARD and G. F. NSOWAH* \\ Welsh Plant Breeding Station, Aberystwyth
}

Received 20.xi.68

\section{INTRODUCTION}

PREvious papers in this series have reported on the genetic basis of ecotypic differentiation between natural populations of perennial ryegrass collected from the Monmouthshire Moors (Hayward and Breese, 1966; Hayward, 1957; Hayward and Breese, 1968). The results so far indicate that differentiation may involve not only the nuclear genetic constitution, but also an important extranuclear component based on the plasmon (see Breese, Hayward and Thomas, 1965).

The mating design for the first experiment was a complete diallel cross. Because of the number of crosses involved the populations could not be sampled in a manner which would allow within-population heterogeneity to be adequately assessed. The present scheme sought to rectify this by adopting a partial diallel crossing system. The reduced number of crosses required by this design enabled a sample of five genotypes from each population to be included as distinct entities. The evidence on variation within populations obtained in this way, however, was only achieved at the expense of information on gene interaction and specific reciprocal effects of the omitted crosses.

\section{MAterial AND METHOD of ANALysis}

The ten populations, each of five genotypes, utilised in the previous study were divided into two groups $\mathrm{A}$ and $\mathrm{B}$; the former comprised populations 6-10 inclusively whilst the latter consisted of populations 1-5. Full details of the origin of these populations and the ecological characteristics of the habitats from which they were collected are given in the papers by Hayward and Breese (1966) and Breese and Charles (1962). Each mating group consisted of one genotype from each of the five populations, those of group A being crossed in all possible combinations with those of group $\mathrm{B}$, including reciprocals; i.e. in the form of the North Carolina Model II of Comstock and Robinson (1952). Five mating groups or diallels were thus formed, each of 50 families. The technique of crossing adopted, automatic cross-pollination without emasculation, was the same as that of the previous study.

The seed of each of the 250 families was sown in the glasshouse in a randomised block design with two replicates. A number of seedling characters on five plants per replicate family was recorded before transplanting into the field in March 1965.

* Present address: Crops Research Institute, Box 3785, Kumasi, Ghana.

$2 \mathrm{~L}$ 
The form of analysis of family means adopted is based on the expectations of the mean squares as shown in table 1. The sums of squares for the two

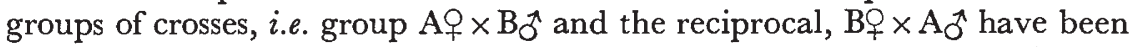
accumulated in order to provide an overall comparison of the ten populations when used as males and females. The one degree of freedom associated with this pooling appears in the table as the reciprocal item measuring an overall effect of direction of cross.

Since each partial diallel is founded on a set of individual genotypes, variability between genotypes within populations will be reflected in the first-order interaction of diallels with other main effects. Such variability may be detected by the comparison of these terms with the basic error. The males $\times$ diallel term detects any additive genetic heterogeneity within the

TABLE 1

Expectations of mean squares for a North Carolina Design II accumulated over reciprocals

Item

Reciprocals (R)

Males (M)

Females (F)

Diallels (D)

$ð \times \mathrm{D}(\mathrm{MD})$

o $\times \mathrm{D}(\mathrm{FD})$

$0 \times+(\mathrm{MF})$

Residual

Male error

Female error

Diallels error d.f.

1

$2(n-1)$

$2(n-1)$

$2(d-1)$

$2(n-1)(d-1)$

$2(n-1)(d-1)$

$2(n-1)^{2}$

$2(n-1)^{2}(d-1)$
Expectations of mean squares

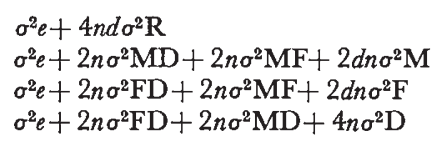

$n=$ Number of populations used as males $=$ number used as females. $d=$ Number of diallels.

populations, whilst the females $\times$ diallels mean square additionally includes heterogeneity in maternal or plasmon variation. The males $\times$ females item may be equated to any specific combining effects, both plasmon and genetic, between the populations. On the other hand, the diallel main effects term ( $=$ the average difference between diallels) reflects genotypic variation within a population only if there is non-random allocation to the individual diallel crosses. The male mean square reveals any population differentiation at the additive nuclear level, whilst the female item measures the same genetic effect and any additional maternal action which may be operative. These main effects may only be tested by comparison with their first-order interactions, where only one of those interactions in which they are involved is significant (see table 1). If more than one of these interactions is significant only an approximate test is available. For this purpose a composite mean square, obtained from the sum of the components and error of the interaction terms, may be utilised (table 1). These appear in the tables of analyses as male, female and diallel errors with degrees of freedom no greater than any of the individual interactions.

As the number of plants per replicate family had been reduced to an average of three due to severe winter killing, the analysis of the field characters (tables 4 and 5 ) has been on a family mean basis after pooling the two 
replicates. The error item in the tables thus represents the accumulated interaction of males, females and diallels within reciprocals.

\section{Results}

\section{(i) Seedling characters}

The characters studied were leaf and tiller production at 63 days, tiller production at 93 days and the length of the 5 th leaf on the main tiller at 73 days after sowing.

The analyses of variance of leaf length and number are shown in table 2, whilst the two tiller counts have been combined and the results are presented in table 3. In all analyses the items of the second-order interaction were not significant when tested against the basic error and have been combined with the latter to form the error term appearing in the tables.

TABLE 2

Analyses of variance of leaf length and number

\begin{tabular}{|c|c|c|c|c|c|}
\hline \multirow[b]{2}{*}{ Item } & \multirow[b]{2}{*}{ d.f. } & \multicolumn{2}{|c|}{ Number of leaves } & \multicolumn{2}{|c|}{ Length of 5 th leaf } \\
\hline & & Sum of squares & Mean square & Sum of squares & Mean square \\
\hline Females & 8 & $240 \cdot 87$ & $30 \cdot 12^{*}$ & 436.95 & $54 \cdot 62 * * *$ \\
\hline Males & 8 & $95 \cdot 73$ & 11.97 & $124 \cdot 85$ & $15 \cdot 61$ \\
\hline Diallels & 8 & $117 \cdot 89$ & $14 \cdot 74$ & $259 \cdot 77$ & $32 \cdot 47 *$ \\
\hline Diallels $\times$ Females & 31 & $338 \cdot 87$ & $10 \cdot 93^{* * *}$ & $345 \cdot 35$ & $10 \cdot 79 * *$ \\
\hline Diallels $\times$ Males & 32 & $222 \cdot 91$ & $6 \cdot 96 * * *$ & $281 \cdot 00$ & $8 \cdot 78^{* * *}$ \\
\hline Males $\times$ Females & 32 & $117 \cdot 10$ & $3 \cdot 67 * *$ & $82 \cdot 38$ & $2 \cdot 57 *$ \\
\hline Replicates & 2 & 281.08 & $140 \cdot 54 * * *$ & $19 \cdot 10$ & $9 \cdot 55 *$ \\
\hline Reciprocals & 1 & $7 \cdot 67$ & $7 \cdot 67 * *$ & 1 & 1 \\
\hline Error & 304 & $544 \cdot 86$ & $1 \cdot 78$ & $618 \cdot 6$ & $2 \cdot 03$ \\
\hline Female error & 32 & - & $12 \cdot 82$ & - & 11.33 \\
\hline Male error & 32 & - & 8.85 & - & $9 \cdot 32$ \\
\hline Diallel error & 32 & 一 & $16 \cdot 11$ & - & $17 \cdot 54$ \\
\hline
\end{tabular}

For both leaf characters the interaction mean squares of males and females with diallels are significant providing good evidence that the genotypes used to sample the populations are distinct, as we might expect in this outbreeding species. Non-additive variation may also be present as the males $\times$ females interaction is significant. In view of the fact that the interactions are significant throughout, the main effects may only be tested against the composite mean square as stated in the description of the analysis. Application of this test reveals that there may well be plasmon differentiation between the populations as only the females main effect is significant. As the test for these main effects is somewhat arbitrary, the 5 per cent. level of significance for the number of leaves should be treated with caution.

The analysis of the first and second tiller counts is given in table 3 . In contrast to the seedling leaf characters the only significant interactions are those involving the female effect. Such a source of variation may be attributable to the direct action of the maternal parent through such factors as seed characteristics, or alternatively through the female plasmon, as there is no evidence of any genetic variation, since the male items are both non-significant. The extent of these female effects alters with time, as shown by the 
significant females $x$ counts interaction. These within-population female effects may well account for the significant diallels main effect due to the non-random allocation of the female effects to the separate diallels. The overall male main effect is of border line significance indicating that the populations may be genetically distinct.

TABLE 3

\begin{tabular}{|c|c|c|c|c|}
\hline \multicolumn{5}{|c|}{ Analysis of variance of first and second tiller count } \\
\hline Item & d.f. & S.S. & M.S. & V.R. \\
\hline Males & 8 & 500 & $62 \cdot 5$ & $2 \cdot 10^{*}$ \\
\hline Females & 8 & 1,278 & $159 \cdot 75$ & $1 \cdot 27$ \\
\hline Diallels & 8 & 984 & $123 \cdot 00$ & $4 \cdot 13^{* * *}$ \\
\hline Counts & I & 52,795 & 52,795 & $1,774^{* * *}$ \\
\hline Replicates & 2 & 100 & $50 \cdot 00$ & $1 \cdot 68$ \\
\hline Reciprocals & 1 & 15 & $15 \cdot 00$ & l \\
\hline$M \times D$ & 32 & 1,125 & $35 \cdot 00$ & $1 \cdot 176$ \\
\hline$F \times D$ & 31 & 1,868 & $60 \cdot 25$ & $2 \cdot 025^{*}$ \\
\hline $\mathbf{M} \times \mathbf{F}$ & 32 & 659 & $20 \cdot 50$ & $\mathrm{l}$ \\
\hline $\mathrm{M} \times \mathrm{C}$ & 8 & 304 & $38 \cdot 00$ & $1 \cdot 277$ \\
\hline $\mathrm{F} \times \mathrm{C}$ & 8 & 764 & $95 \cdot 50$ & $3 \cdot 21 * *$ \\
\hline Error & 288 & 8,565 & $29 \cdot 75$ & - \\
\hline Female error & 31 & - & $126 \cdot 00$ & - \\
\hline
\end{tabular}

(ii) Date of inflorescence emergence

The date of inflorescence emergence was recorded during the summer of 1966 after the plants had received full induction during the previous winter. The analysis of the data, pooled over the two replicates, is shown in table 4.

TABLE 4

Date of inflorescence emergence

\begin{tabular}{|c|c|c|c|c|}
\hline & d.f. & S.S. & Mean square & V.R. \\
\hline Females & 8 & $980 \cdot 80$ & $122 \cdot 60$ & $2 \cdot 68 *$ \\
\hline Males & 8 & $492 \cdot 00$ & $61 \cdot 50$ & $2 \cdot 23^{*}$ \\
\hline Diallels & 8 & $2298 \cdot 00$ & $287 \cdot 25$ & $5 \cdot 71 * * *$ \\
\hline Diallels $\times$ Females & 31 & $1224 \cdot 64$ & $38 \cdot 27$ & $4.957 * * *$ \\
\hline Diallels $\times$ Males & 32 & $631 \cdot 68$ & $19 \cdot 74$ & $2 \cdot 556 * * *$ \\
\hline Males $\times$ Females & 32 & $486 \cdot 40$ & $15 \cdot 20$ & $1 \cdot 968 * *$ \\
\hline Reciprocals & 1 & $35 \cdot 00$ & $35 \cdot 00$ & $4 \cdot 530 *$ \\
\hline Error & 97 & $749 \cdot 00$ & $7 \cdot 72$ & - \\
\hline Female error & 32 & - & $45 \cdot 75$ & - \\
\hline Male error & 32 & - & $27 \cdot 22$ & - \\
\hline Diallel error & 32 & - & $50 \cdot 29$ & - \\
\hline
\end{tabular}

Here again, heterogeneity between constituent genotypes of the populations is shown by the significant males $\times$ diallels item. The females $\times$ diallels mean square is significantly greater than the males $\times$ diallels, indicating that in addition to nuclear genetic variation there also exists plasmon differentiation between plants within a population. There may well be some specific 
differentiation, as the males $\times$ females interaction is significant. It is not possible to ascertain the causal effect of this item, as it represents both specific genetic interaction, i.e. dominance or epistasis and nuclear cytoplasmic interaction. This difficulty similarly applies to the diallels item which, in this instance, represents residual nuclear or cytoplasmic variation between clones. Such variation may well be associated with the differential heading times of the original plants (see Breese and Charles, 1962; Hayward, 1967) and the consequent assortative mating necessary during crossing.

Both the female and male main effects are significant when tested against their appropriate compound errors, suggesting that the populations are genetically distinct. As the female mean square is no greater than the male mean square there is no evidence here of any plasmon differentiation.

TABle 5

Analysis of variance of hay and aftermath production

\begin{tabular}{|c|c|c|c|c|c|}
\hline \multirow[b]{2}{*}{ Item } & \multirow[b]{2}{*}{ d.f. } & \multicolumn{2}{|c|}{ Hay cut } & \multicolumn{2}{|c|}{ Aftermath cut } \\
\hline & & Sum of squares & Mean square & Sum of squares & Mean square \\
\hline Females & 8 & 636,784 & $79,598^{* *}$ & 121,848 & $15,231^{* * *}$ \\
\hline Males & 8 & 393,432 & 49,179 & 66,424 & $8,303^{* * *}$ \\
\hline Diallels & 8 & 430,930 & 53,866 & 40,280 & $5,035^{* *}$ \\
\hline Diallels $\times$ Females & 31 & 765,730 & $23,929^{*}$ & 71,615 & 2,238 \\
\hline Diallels $\times$ Males & 32 & $1,213,600$ & $37,925 * *$ & 36,256 & 1,133 \\
\hline Females $\times$ Males & 32 & 298,464 & 9,327 & 63,200 & 1,975 \\
\hline Reciprocals & 1 & 806 & 806 & 126 & 126 \\
\hline Error & 97 & $1,260,356$ & 12,993 & 170,000 & 1,752 \\
\hline Diallel error & 32 & - & 48,861 & - & - \\
\hline
\end{tabular}

(iii) Productivity

The total yield of green material produced was recorded for a hay and aftermath cut during the summer of 1966, the results of the analysis of variance of which are shown in table 5 .

For the hay cut there is again proof of heterogeneity within populations, as both the male and female interactions with diallels are significant when tested against the residual error, thus confirming once more that the individual tiller bunches collected from the pasture were in fact distinct genotypes. Although the males $\times$ diallels mean square is the largest, it is not significantly greater than the females $x$ diallels mean square; in examination of the main effects, therefore, each item has been compared with its corresponding interaction. Application of these tests reveals that only the females term is significant, suggesting that with regard to this character the populations may well be differentiated at the plasmon level.

The diallels mean square is non-significant when tested against its compound error. This indicates that, irrespective of the variation within populations, the allocation of the genotypes to the individual diallels was random for this character.

Turning to consider the aftermath production, a somewhat different picture is apparent, for here the interaction terms are all non-significant (see table 5). This would immediately indicate that the individuals within a 
population are homogeneous for this character; although, as the diallels main effect is significant, there may well be some variation as revealed by this non-random allocation of genotypes to the individual diallel crosses. Both of the main effects are significant and, as that for females is no greater than that for males, it is probable that variability in this instance can be ascribed entirely to nuclear control.

\section{Discussion}

The general objectives of the present study were to investigate the genetic basis of population differentiation between ten natural populations of Lolium perenne, and more particularly in this section, to obtain a measure of within population heterogeneity. In that the results presented here also provide information on between population variability, these will at the same time be considered in relation to those previously published (Hayward and Breese, 1966; Hayward, 1967; Hayward and Breese, 1968).

\section{Differences within populations}

In so far as Lolium perenne has a vigorous outbreeding mechanism it must be expected that individuals will be heterozygous and that populations will have retained considerable potential variability. It is evident from the analyses presented here that significant variation exists between the individuals within each population for all seedling characters. For the leaf characters, this variability is nuclear-genetic in origin, whilst for the tiller production it may well be under the control of the plasmon. Turning to consider the adult plant characters, for the timing of inflorescence emergence there is good evidence of both nuclear and plasmon variation within the populations. Analysis of the productivity data reveals nuclear variation only for the hay cut, while for the aftermath cut no significant heterogeneity may be detected.

This evidence lends substance to the contention by Breese and Charles (1962) that the phenotypic uniformity of their vegetatively-reproduced collections within the populations was not due to repeated sampling of the same genotype. Although perennial ryegrass can maintain itself for long periods in these old pastures by vegetative reproduction, quite clearly it does not spread to any great extent, unlike the Festuca rubra reported by Harberd (1961). Considering that neither these nor the previous studies have shown any marked differentiation between populations at the nuclear level, we have to assume that adaptation has been achieved through some form of genotypic plasticity (see also Bradshaw, 1965). It has already been proposed that this plasticity may in part be predisposed by a variable plasmon (Breese et al., 1965). It is thus of particular interest that the present study reveals evidence of extranuclear factors controlling variation between individuals. It forms a link between the tiller variability of Breese et al. (loc. cit.) and the apparent plasmon differentiation of the populations demonstrated in this and the earlier studies.

\section{Differences between populations}

In contrast to the overall population differences for all seedling characters measured by Hayward and Breese (1966), the only significant effect in the present study is that attributable to possible plasmon variation. The 
previous results indicated that the population differences were mainly under additive genetic control, the only indication of plasmon effects being specific nuclear/cytoplasmic interactions for the leaf number character. A similar anomaly applies to the timing of inflorescence emergence in that previously both additive genetic and plasmon effects were operative (Hayward, 1967) whilst here only the former process is apparent. The productivity characters present a similar picture in that both additive genetic and plasmon effects were present and constant in their action over the two cuts. Here, however, only plasmon differentiation is present at the hay cut and only additive variation at the aftermath cut.

These apparent anomalies in the results of the two analyses may be accounted for by the mating schemes adopted and the criteria applied for the establishment of population differences. As stated, the initial study consisted of a complete $10 \times 10$ diallel crossing scheme at the population level, as crosses of individual genotypes had been pooled. Here only a partial diallel system was adopted in that the ten populations were divided into two groups of five each, which were then intercrossed with one another. This latter design gave rise to only 50 population crosses compared with the 100 of the previous study. This restricted the available population comparisons to those between the two mating groups, as the crosses within any one group were absent. This may well account for some of the differences in the two sets of results. In addition, the present experiment provides a more sensitive, although limited test, for the establishment of population differentiation in that all comparisons are made against variation within populations unlike the earlier experiment, where the main effects were tested against their replicate interaction.

\section{Population structure}

The present studies unveil some interesting features of population structure in the persistent ryegrasses which could not be assessed from the initial investigations.

As may be expected for a predominantly outbreeding organism, there is considerable heterogeneity between individuals within a population for some of the characters measured. The results of Cooper (1959), on selection for timing of inflorescence emergence from within two populations of Lolium perenne, amply demonstrated the existence of considerable additive nuclear variation present between very few individuals. Here, however, the results indicate that not only is there nuclear variation present, but also plasmon variability for some of the characters. The relatively simple additive variation in these populations would suggest that in this species differentiation is not accompanied by the evolution of a delicately adjusted genetic system which we have come to expect from studies on Drosophila and other sexually reproduced organisms (Mather, 1953).

The existence of plasmon variation between genotypes, in addition to that previously described at the population level, adds a further dimension to the control of variation in these populations. The phenotypic uniformity within a population does not, therefore, imply either genotypic or plasmatypic constancy. Observations on swards with a known history of management have also indicated a similar pattern of variation (Hayward, 1968).

In conclusion, the results presented here lend support to our previous proposal that in the absence of regular sexual reproduction, differentiation 
had come about by the action of selection on both the nucleus and plasmon Furthermore, they emphasise once again the importance of the interaction and interdependence of this dual control of variability.

\section{Summary}

1. The genetic control of variation within and between a series of natural populations of Lolium perenne L. has been examined, utilising a partial diallel crossing scheme.

2. Both within and between, population variability for seedling, inflorescence, and adult plant productivity characters is under nuclear genetic and plasmon control.

3. These results confirm and extend those previously obtained, and emphasise the importance of joint nuclear and plasmon control in predominantly vegetatively reproduced populations of ryegrass.

Acknowledgments.-We wish to thank Professor P. T. Thomas and Dr E. L. Breese for their interest and guidance during this work. One of us (G. F. N.) acknowledges the receipt of a grant from the British Council which enabled this project to be undertaken as part fulfilment of a Ph.D. degree of the University of Wales.

\section{REFERENCES}

BRADSHAW, A. W. 1965. Evolutionary significance of phenotypic plasticity in plants. Adv. in Genetics, 13, 115-155.

BReEse, E. L., AND Charles, A. H. 1962. Population studies in ryegrass. Rep. Welsh Pl. Breed. Stn for 1959, 30-34.

BREESE, E. L., HAYWARD, M. D., AND THOMAS, A. C. 1965. Somatic selection in perennial ryegrass. Heredity, Lond., 20, 367-379.

COMSTOCK, R. E., AND ROBINSON, H. F. 1952. Estimation of average dominance of genes. In Heterosis, pp. 494-516. Ames Iowa State Coll. Press.

COOPER, J. P. 1959. Selection and population structure in Lolium. III. Selection for date of ear emergence. Heredity, Lond., 13, 461-479.

HARBERD, D. J. 1961. Observations on population structure and longevity of Festuca rubra L. New Phytol., 60, 184-206.

HAYWARD, M. D. 1967. The genetic organisation of natural populations of Lolium perenne. II. Inflorescence production. Heredity, Lond., 22, 105-116.

HAYWARD, M. D. 1968. Genetic composition of survivor populations of perennial ryegrass. Rep. Welsh Pl. Breed. Stn for 1967, 33-35.

HAYWARD, M. D., AND BREESE, E. L. 1966. The genetic organisation of natural populations of Lolium perenne. I. Seed and seedling characters. Heredity, Lond., 21, 287-304.

HAYWARD, M. D., AND BREESE, E. L. 1968. The genetic organisation of natural populations of Lolium perenne L. III. Productivity. Heredity, Lond., 23, 357-368.

MATHER, K. 1953. The genetical structure of populations. Symp. Soc. Exp. Biol., 7, 66-95. 